\title{
Diacrises and mixed emotions in the relationship between music and art cinema: teacher learning and training through multimodal experiences
}

\author{
Gianni Nuti \\ University of Aosta Valley, Italy,g.nuti@univda.it,ORCID 0000-0001-7928-0161
}

\begin{abstract}
The study discusses the ability to develop metacognitive skills through experiences of contact with cinematic works that produce complex, multifaceted, emotional impacts understood by the body before they are understood by the mind. We investigate the relationship between music and images by identifying morphological profiles and the multimodal value of hybridized, dynamic and mutually changing phenomena [Zambaldi, 2016] in which we see ourselves [Gallese, Guerra, 2015]. We must emphasize that only by elaborating propositions, reordering reality according to grammatical codes and syntactic patterns, it is possible to circumscribe and amplify the power of communication and non-verbal relationships: the power of embodied cognition must not stop but foster the power of words
\end{abstract}

Keywords: Didactics and pedagogy of art, Visual narrative, Mixed emotions, Thought and representation, Teacher training.

\section{Introduction}

The ability to develop metacognitive skills is, according to the Vygotsky paradigm, closely related to the dimension of intersubjective relationships and social interactions [1. Rogoff and Wetsch, 1984, 2. Wetsch, 1985]. The ability to recognize the mechanism of one's condition and that of others, the ability to regulate them by allowing them to govern learning and to optimize adaptive processes by resolving problems and an appropriate and timely reaction to surrounding socio-environmental changes are determined only by means of exchanges, sharing and contrast between humans living together. By extensive and non-contradictory logic, it must be argued that mediated relationships can also allow for the maturation of the skills we speak of, especially those with artistic works. We are talking about works of art not just simple artefacts, mass productions, good craftsmanship, because if both have the ability to symbolize vital experiences, stylize their traits, reproduce their organics and their complex substance, limiting space-temporal coordinates and adopting precise linguistic - expressive codes, for the first time, the meanings are multiplied and regenerated permanently [3. Simpson, 1998], styles gain persistence over time and an erosion resistance spreads throughout the world. Thus, as Paolo Orefice argues, "the evolutionary dynamics of the process of development is always activated by a need to explore reality which engages the biopsychic forces of the subject in an attempt to draw and elaborate interpretative solutions" [4. Striano, 2000], then, if the concept of reality is transposed to an experiential dimension within a representation that opens a profound, coherent and multifaceted scenario, art is the field where learning is rooted in the exchange between living things and it triggers a hermeneutic need that calls for exhaustive but provisional answers, since these refer to continuous, additional questions in a lifelong, self-generating and innovative cycle. In addition, the educational and training power constituted, even implicitly, by direct or indirect artistic experience represents a consolidated assumption in pedagogical sciences [5. Read, 1958; Gardner, 2005).

For this reason, art is not only the formal result of a series of metacognitive processes but also an elective place for a man to learn and understand himself while living, working and loving. 


\section{Diacrises and mixed emotions in the relationship between music and art cinema: teacher learning and training through multimodal experiences \\ Nuti}

We want to focus on how art cinema can contribute to refining that part of metacognitive skills that allow for the domination of temporality, namely the ability to predict/project and plan actions by projecting thought into the future or to monitor and activate evaluation and self-valuation processes by casting a retrospective glance over the past [6. Ciappei, Cinque, 2014]. However, as Rivoltella reminds us that cinema cannot be regarded as performing art if we embrace Pradier's thesis, according to which performing refers to those "body scene" arts in which the reversibility and repeatability of the event are lacking; if we consider the fact that the central knot of the seventh art is not just staging the act, but inducing the spectator to do it, with unparalleled identification and mirroring power, then we deal with performing art par excellence. Thus, an art representing moving, dynamic, contextualized events powered by tense/calm elements promotes a mediated approach to temporality.

The emphasis on the expressive and non-intercommunicative value of cinematographic language is due to Christian Metz [1964] who questions himself for the first time about the possibility of a semiological study of (and in) cinema. This is the coincidence between the signifier and the meaning; the message is immanent and embodied; it is not contained in their interdependence; it is not structured according to a regularity of a syntagmatic and paradigmatic order and shortly, it is not considered essential in the form of a system. This, according to Metz, explains the dimension of universality of cinematographic language and, we add, justifies a research that investigates the direct relationships between emotions and kinematic form between two complex realities, expressions of lives. Moreover, the didactic, educational aesthetic use of cinema, as Agosti [2004] observes, develops a prudent, sacred distance between educational objectives, transmission strategies and the richness and vagueness of the filmic message.

The challenge, however, is to use the art of cinema to refine this cognition of existential time by decoding complex, multifaceted, emotional states understood by the body before they are understood by the mind. The role of emotions in teaching/learning processes was first met with epistemological interest in the psycho-educational [7. Hascher, 2010] and social fields [8. Morin, 2001], reinforced nowadays by neuroscientific discoveries [9. Ledoux, 1996). Moreover, understanding emotions is the outcome of a multi-component and multidimensional construct in which several specific abilities come into play [10. Eschrich et al, 2008] which allow for progressive transition from the experiential dimension [11. Bion, 2009] to the mental and reflective one [12. Moon, 2012], but require developmental reinforcements and awareness-raising processes, in the certainty that the more emotional states are polychromatic and intricate, the more the aforementioned awareness will be relative in the word, authentic in the motions of the animated body.

Indeed, currently, the emotional instinctive reaction that women and men experience before the cinematic language of art and music is more intense when there is no propositional translation is needed in the literature. Intensity is even more powerful when the two codes cooperate together in an integrated way. This expressive complementarity is connected not only to the prevalence of visual-auditory combined stimuli with which the contemporary media landscape is imbued but also to the almost ontological affinity between the two arts where, in both, human perception is compelled to systematically phase out time, to continual diachronies: in cinema between the imprinting determined by the first image and the rapid movement to the subsequent image, in music when one is still enjoying a musical phrase and the next one follows closely, the compositional architecture, however essential, always implies compresences, overlays and interlacing.

This particular use of the relationship between sounds and images can allow for the identification and conceptualized representation of mixed emotional states - in some cases clearly ambivalent - used perfectly in narration and with a high coefficient of expressivity. The multidimensionality of the psycho-evolutionary theory of emotions [13. Plutchik, 2001] recognizes the fluidity of emotional states which, placed within a three-dimensional cone, express opposition, proximity, but also intermingling. The focus of movie and music sequences [14. Cohen, 2001] which, experimenting with preliminary applications of their respective linguistic syntax evoke multimodal and cross modal perceptions, seems to confirm recent neuroscientific research on the relationships between specialized cerebral areas where specific sensory receptors are present and others, such as the superior colliculus, in which activations belonging to several different modal areas converge and interact, by excitation or inhibition [15. Meredith, 2002; 16. Calvert et al., 2000]. This type of decoding exercise concerning a complex symbolic system allows students in training to not only become aware of the many existential experiences that exhibit mixed emotional states but also, above all, to recognize the semantic traits, morphological profiles and multimodal value of the communicative phenomenon that intertwines and blends different and contradictory sensory perceptions into a single hybridized state of dynamic and changeable being [17. Zambaldi, 2016].

Thus, both languages combine divergent temporalities that are manifested in a kinematic manner [17. Lombardo, 2014]. Existential time and its more or less dissonant polyphonic stratifications in which each person lives during everyday life encounter, in a symbolized representation made of plots, elaborate profiles and contours such as cinema, 


\section{Diacrises and mixed emotions in the relationship between music and art cinema: teacher learning and training through multimodal experiences \\ Nuti}

the same ambiguities and similar convolutions to the point of determining and experiencing real fascination [18. Malavasi, Polenghi, Rivoltella, 2005]. This gives way to an analysis of the emotional component that comes into play and constitutes the driving force and the chromatic field of climate in which awareness matures. We are talking about those kinds of mixed emotions, where, for example, joy and sadness, rancour and reconciliation, of antithetical, positive and negative values that are very frequent in real life and fundamental in art experience. This coexistence between represented or suggested emotional phenomena which creates ambivalent correspondence in the spectator is defined by certain philosophers as the paradox of art [19. Carroll, 2011].

\section{Materials and Methods}

This paper documents an empirical study carried out on a sample of 150 students from eight Italian universities and music conservatories who took part in a session during which the selected movie sequences, about 3 minutes each, in particular on the relationship between sounds and images were analyzed. In fact, the group focused on the forms of artistic expression in which some selected film images were in close relation to the soundtracks in contrasting or multimodal approaching tones. The aim was not to mature or experiment technical skills in recognizing forms of cinema language in relation to music, but to refine personal perception of time by studying the relationships between symbolic representation of events, dynamic situations, intersubjective contexts and mixed emotional states whose complexity represents a field still little explored by psychological sciences and even more marginalized in the world of education. The recognition of emotions is in fact pursued by educators mainly in primary school by discrimination, separating one from the other, artificial schematization between primary and secondary education, which obviously makes the verbalization dimension prevalent with respect to digging deep into the complexity of the integrated and truly lived mind-body condition; moreover, what Sroufe [20. 2000] traces back in the child to a more or less intense, but generic, arousal state, not immediately connoted and qualifiable. In fact, starting from primary emotions, projects often aim to foster contact with micro-juxtaposed, often contrasting, and yet strongly connoted experiences to gain recognition and regulation skills of emotional states that are clearly distinct from each other. Indeed, most of the intense experiences undergone are emotionally translatable by people in an ambivalent way: joy has the seed of its fall, fear hides hints of pleasure concealed in danger, tenderness and resentment often coexist, and so on. Moreover, art synthesizes and exalts these anthropic features by giving them beautiful shapes but not just by using its own distinct idioms, but also by inducing different degrees of adherence to a substantial "liberating and expressive" simulation. In the literature, hybridized emotional states are described by juxtapositions, often in oxymoron, in dissonance, releasing, a range of further implicit meanings between two adjectives. The work of a contemporary author, Elena Ferrante, who adopts a terse writing style, is very eloquent in this sense but extremely punctual in describing ordinary daily facts with the eyes of a continual emotional miscegenation. In fact, there are frequent references to emotional ambivalences in her narratives:

"The glasses fell to the floor and immediately I screamed with bitter joy, without slightest trace of dialect:" See what you've done? You've broken my glasses and now because of you I can't study anymore, I won't go to school anymore."'"

"He had the look of someone who is forced to repress joy and fright simultaneously."

"Lila was happy, and she was dragging me into her fiercely happy happiness, especially as she had suddenly come across an opportunity, perhaps without even realizing it, that would allow her to be a fury against herself, the onset of the need, perhaps for the first time in her life, - and here the verb used by Michele was appropriate - to wipe herself out."

"I imagined a wayward Lila who inspired hate deliberately ending up increasingly involved in fierce actions. Of course she had the courage to go further, to take the initiative with crystal clear determination, with the generous cruelty of those who are animated by a just cause."

But in cinema, the process of identification, the suspension of our discernment between reality and fiction, is more visceral and intense, holistic not only because it is multisensory but also because it reproduces, in a very plausible way, what happens in neonatal life when our limited movements have to develop neural circuits of reflection before action, forcing us into immobility, allowing us to concentrate our vital energies on living reality through the bodies of others, by changing our world view in a neo-genetic way [21. Gallese, Guerra, 2015].

This is the reason why metacognitive learning and the recognition of mixed emotions [22. Varani, 2000] find the ideal setting in cinematic experience: in the face of meta-reality in which I can simulate my own, I can learn to 


\section{Diacrises and mixed emotions in the relationship between music and art cinema: teacher learning and training through multimodal experiences \\ Nuti}

understand how my body, in its entirety that does not distinguish the mind from the flesh, reacts and adapts, to the surrounding dynamic phenomena.

The choice of film sequences for this experimentation was directed at a prevailing aesthetic code, linked to the Proustian "sense of time" structured in diverse ways. Four movie sequences filmed by four Italian directors from different periods presenting several common denominators were chosen: Federico Fellini's The Road, Ermanno Olmi's The Tree of Wooden Clogs, Giuseppe Tornatore's Cinema Paradiso and Nanni Moretti's The Son's Room.

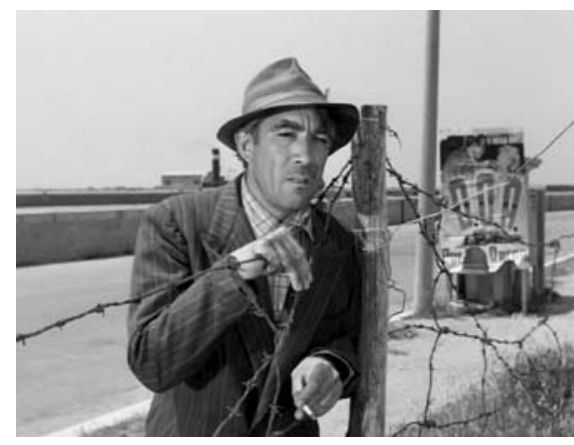

(a)

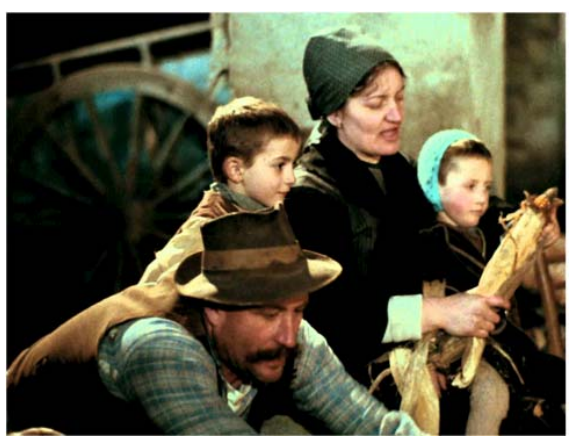

(b)

Fig. 1 The first two film sequences: (a) The Road, Federico Fellini (1954): Zampanò (Antony Quinn) listening to Gelsomina's song sung by a housewife when he finds out that she had died a few years earlier; (b) The Tree of Wooden Clogs, Ermanno Olmi (1978): The family has got together to shuck corn and sing traditional songs.

In the first scene, Zampano's cart abandons Gelsomina in the middle of winter among ruins, inland on the hills in Romagna, while the film's theme song written by Nino Rota plays as a background to their farewell. Immediately after we see Zampanò arriving on the coast with his new group of drifters and, walking along the road that runs along the beach, he hears a young woman singing Gelsomina's song as she hangs out the washing: he lights up with joy, asks for news and hears that the girl had died of a broken heart a few years earlier (see Figure 1.a).

The second scene features a family in Bergamo at work in daily life during the late nineteenth century. It begins with the birth of a foal and ends with a goose being slaughtered, all within the bustling life bound by the walls of the farmhouse, rich in micro-events, children's games and adult industriousness. During the entire scene, an excerpt from Bach's Fugue in G minor, BWV 131a plays in the background. Immediately after, the whole household is seen in the evening, sitting in a circle shucking corn and singing a folk song, Moretto Moretto, a story of love, made fonder by distance (see Figure 1.b)

Moretto Moretto a fine young lad

With hair as wavy as the sea

His boat sped over the swelling waves

Moretto was calling Ninetta come to me (...)

The third episode sees little Totò playing his role as assistant to Alfredo, the projectionist at Ciancaldo's parish cinema during a newsreel in which he sees an image of his father, a war victim (Figure 2.a): the boy earmarks this image on the film reel as he rewinds it. The change in shot opens out onto a view of the bombed town: Totò is coming out of the town hall with his mother where the death of his father/her husband has just been made official, she is grieving and crying with dignity, while the boy looks at her without anguish and then is rapt by a Gone with the Wind poster affixed to the wall of a ruined house. The main theme of Ennio Morricone's soundtrack plays on end permeating the entire sequence.

The fourth and final sequence sees Nanni Moretti (Figure 2.b) going to his son's favourite record shop, (the boy had drowned during a scuba diving lesson), to "buy him a present" on his birthday; the shop assistant, embarrassed, recommends a $\mathrm{CD}$ that the boy surely would have loved and plays the opening. While the protagonist stops short and then leaves the shop alone, looking grim we hear, first as diegetic then as non-diegetic sound the opening of By This River, taken from Brian Eno's 1977 album "Before and After Science". 


\section{Diacrises and mixed emotions in the relationship between music and art cinema: teacher learning and training through multimodal experiences

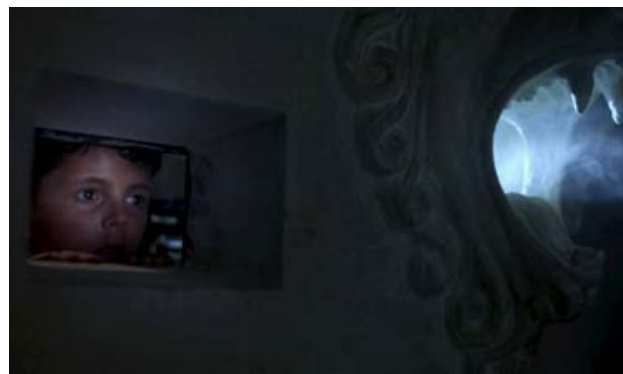

(a)

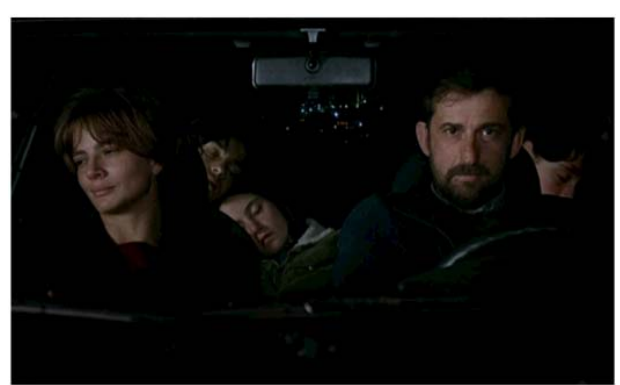

(b)

Fig. 2 The last two film sequences: (a) Cinema Paradiso, Giuseppe Tornatore (1988): Totò discovers from a news story that he himself is projecting that his father had died during the war; (b) The Son's Room Nanni Moretti (2001): The family is still close-knit before the tragedy takes place: we can sense foreboding from the protagonist's expression.

Here we are

Stuck by this river,

You and I

Underneath a sky that's ever falling down, down, down Ever falling down.

\author{
Siamo qui \\ ipnotizzati da questo fiume \\ tu ed io \\ sotto un cielo che continua a cadere, cadere giù \\ continua a cadere giù.
}

Each film clip was introduced by a short summary of the plot in which the sequence is included, avoiding both explicit opinions regarding the film and any type of hermeneutic interpretation.

Instructions were only to identify emotional states and emerging meanings determined by the temporal relationship between music and image.

After each excerpt, a 20-minute brainstorming exercise was recorded with a digital device and then transcribed using Dragon Naturally Speaking, a speech recognition software.

Each transcript was then processed by an online text analyzer (www.lexicool.com) to measure lexical frequencies.

At the end of the activities, a questionnaire was administered to the students involved, concerning both how much they had enjoyed the experience and their perception of what they had learnt in terms of:

- ability and level of detailed analysis concerning relationships between music and film images;

- level of self-awareness regarding emotional states experienced during vision and then in the phase of collective analysis and shared conceptualization during the brainstorming exercise;

- ability to compare the temporal organization of the sound elements with respect to the images of both the events represented and editing;

- level and quality of any spillover that such an experience might have on teaching.

\section{Results}

553,350 words having 3,552,750 letters from approximately 900 pages of brainstorming transcripts were processed and analyzed. The number of different words used was 225,213 having a lexical density of $40.7 \%$. The average length of the locutions was 21.76 words, the longest made up of 234 words. The texts were analyzed both sequence by sequence and as a whole.

For the first film sequence, after the most frequent words, unimportant words had been removed, the most frequent words were not only memory, death, loss, guilt and desolation but also duration, prolongation and eternity (see Table $1)$.

\begin{tabular}{|l|l|l|}
\hline Word & Frequency & Prominence \\
\hline Memory & $4.9 \%$ & 47.6 \\
\hline Death & $4.9 \%$ & 78.6 \\
\hline
\end{tabular}


Diacrises and mixed emotions in the relationship between music and art cinema: teacher learning and training through multimodal experiences

\begin{tabular}{|l|l|l|}
\hline \multicolumn{3}{|c}{ Nuti } \\
\hline Loss & $3 \%$ & 45.5 \\
\hline Guilt & $2.5 \%$ & 43.2 \\
\hline Desolation & $2 \%$ & 50 \\
\hline Duration & $1.5 \%$ & 43 \\
\hline Prolongation & $1.5 \%$ & 47 \\
\hline Eternity & $1 \%$ & 60.1 \\
\hline
\end{tabular}

Table 1.

Next, the most frequent phrases that contained descriptions of mixed emotional states, such as gentle sadness referring to the memory scene - silent tragedy - with respect to history - soft-hearted toughness, in describing Zampanò's state of mind were identified.

Expressions connected to profiles and geometries represented symbolically by related images and sounds which can create morphological correspondences with perceived emotional states, emerged. In particular, repeatedly emphasized in reference to the leit motifs, were the suspense created by the melopoeia, the progressive descending sequence "like a falling leaf", its distant source with the addition of a slow and rising voice, the correlation between feeling nostalgic, the purity of the soul and yearning expressed in the musical theme in apparent contrast with the hardness of Zampanò's face, barely broken by unspoken pain.

The temporal relationship between music and image was retrospective for the majority of the group in question, despite the fact that both the cart in the first scene and Zampanò in the second appear as moving forward towards the future.

For the second sequence, the keywords were life, death, cycle, religious, recollection, mystical, normality and sacredness (see Table 2).

\begin{tabular}{lll}
\hline Word & Frequency & Prominence \\
\hline Death & $3.8 \%$ & 64.2 \\
Life & $2.9 \%$ & 55.2 \\
Cycle & $2.8 \%$ & 51 \\
Religious & $2.5 \%$ & 54.8 \\
Recollection & $2 \%$ & 56.3 \\
Mystical & $1.6 \%$ & 49.4 \\
Sacredness & $1 \%$ & 56.3 \\
Normality & $0.4 \%$ & 17.8 \\
\hline
\end{tabular}

Table 2.

The most significant mixed emotional states were innocent horror, weightless struggle and forced prayer.

Image and sound profiles were teeming, chases, broken lines in pictures, interlacing in music, density of actions and saturation of the music during the first scene, slow circularity in the second.

Diachronies between the events narrated through image related to the temporal relationship between music and image were noted: prosaic, scenes marked by natural rhythms, projected towards chronological flux and Bach's music, enveloped in an endless, intense portrayal of time.

The words that emerged from the third sequence were loss, mourning, lightness, hope, future and astonishment (see Table 3).

\begin{tabular}{lll}
\hline Word & Frequency & Prominence \\
\hline Loss & $6.3 \%$ & 53.8 \\
Mourning & $4.7 \%$ & 49.3
\end{tabular}


Diacrises and mixed emotions in the relationship between music and art cinema: teacher learning and training through multimodal experiences

\begin{tabular}{lll} 
& \multicolumn{3}{c}{ Nuti } \\
Lightness & $2 \%$ & 43.4 \\
Hope & $1.5 \%$ & 46.7 \\
Future & $1 \%$ & 39.8 \\
Astonishment & $0.4 \%$ & 50 \\
\hline
\end{tabular}

Table 3 .

The most interesting mixed emotional states were smiling regret, desperate hope and painful excitement.

The images first focus on the moment when the boy's father's death is revealed by his appearance in the film, then they flow forward towards a symbol that prefigures the future and proclaims a vocation; the soundtrack swans continuously over the staged events slowly then progressively rises and sheds, over the course of the journey, a melancholic, pervasive and ambivalent aura: melancholic and reassuring, linked to an evocation of lost time and the lightness which follows complete self-realization.

The fourth sequence marks the prominence of these words: pain, regret, atonement, downfall, precipitation, inconsolability.

\begin{tabular}{lll}
\hline Word & Frequency & Prominence \\
\hline Pain & $5.1 \%$ & 50.6 \\
Regret & $3.9 \%$ & 49.2 \\
Atonement & $3 \%$ & 41.1 \\
Downfall & $2.7 \%$ & 53.3 \\
Precipitation & $2 \%$ & 37.8 \\
Inconsolability & $1 \%$ & 34.3 \\
\hline
\end{tabular}

Table 4.

Mixed emotional states were sad irony, a sense of motionless motion, of being filled with emptiness and desperate hope.

The profiles are all oriented towards the descent, the deafening fall, marked by the stark, weary gloomy descending melody and towards the protagonist's walking away alone his face fixed in a ghostly steadiness.

The transversal elements present in the four sequences mark the close relationship between the experience of liminal temporality, the one that interweaves recollection of the past with the fleeting present and casts foreboding on an uncertain future created by overlapping, contrasting, oxymoronic audiovisual languages with the manifestation of mixed emotional states: loss, reminiscence and hope coexist in a mix of figures and images that concentrate several perceptions of time in a single moment.

\section{Discussion}

From the questionnaire given to participants, a convincing interest in this form of media experience emerges ( $90.5 \%$ between very and extreme); $65 \%$ declared that they learnt to examine in depth, using new tools, film excerpts appreciating their profoundness; $70 \%$ recognized that there was a correlation between the time profiles identified together when analyzing the scenes in relation to the music and the emotional states experienced: an idea of time is reflected on everyone's life thanks to the empathic relationship generated by interweaving music and images. $49.6 \%$ said that they acquired increasing understanding when interpreting audiovisual experiences from the first to the fourth sequence; $63.6 \%$ claimed to have increased their ability to (two items out of three could be ticked):

interpret the relationship between music profiles and geometries of moving images $(46.2 \%)$

identify mixed emotional states mirrored in the selected sequences $(61.8 \%)$

connect perceptions of time to expressive meanings of the media event attended $(50.1 \%)$

$92 \%$ of interviewees affirmed the positivity of using awareness-raising processes in educational relationships, while $69.3 \%$ said that they wanted to adopt similar methods in their teaching. Such sensitivity corresponds to the 


\section{Diacrises and mixed emotions in the relationship between music and art cinema: teacher learning and training through multimodal experiences \\ Nuti}

perceived need of acquiring knowledge of aesthetic communication [21. Biasci et al., 2004] in educational contexts and training of use in building individual and social subjectivity in the contemporary world.

\section{Conclusions}

The recent awareness in the world of cognitive sciences and education, but long standing in the field of art, of how knowledge does not only have its conscious resonator in words, the conductors of information, of elements, of expressive insights because embodied cognition produces multi-fold evolutions, indispensable adaptations in the life of every human being, must not stop, but foster the power of the probing word.

It is precisely through the effort of conceptualizing and developing propositions which reorder reality according to grammatical codes and syntactic patterns, where the power of communication and non-verbal relations can be circumscribed and amplified. Only by identifying what words have the power to express can the emergence of the unsaid which is facilitated, not only because it is imprisoned in an arcane casing but also because it is able to penetrate into the flesh without mediation.

Hence, talking about artwork to better understand cannot only be a clever display of skill between the acolytes of critics and scholars' clubs but should be encouraged and popularized as a means of bringing a multitude of intense emotional experiences into people's lives because they are supported by reasoning and freed by the pleasure that "the indetermined", the ineffable moves in the embodied living of each person, beyond words.

\section{References}

Agosti, A. (Ed.). (2004). Il cinema per la formazione: argomentazioni pedagogiche e indicazioni didattiche (Vol. 6). Milano: FrancoAngeli.

Biasci, V. \& Bonaiuto, P. \& Cordellieri, P. (2004). La componente estetica nella comunicazione didattica. TD Tecnologie Didattiche, 1, 4-13.

Bion, W. R. (2009). Apprendere dall'esperienza. Roma: Armando Editore.

Carroll, N. (2011). La Filosofia del Cinema. Roma: Dino Audino Editore.

Ciappei, C. \& Cinque, M. (2014). Soft Skills per il governo dell'agire. La saggezza e le competenze prassicopragmatiche, Milano: Franco Angeli.

Cohen, A. J. (2001). Music as a source of emotion in film. Music and emotion: Theory and research, 249-272.

Gallese V., Guerra M. (2015). Lo schermo empatico. Cinema e neuroscienze. Milano: Raffaello Cortina.

Gardner, H. (2005). Educazione e sviluppo della mente. Intelligenze multiple e apprendimento. Trento: Edizioni Erickson.

Hascher, T. (2010). Learning and Emotion: perspectives for theory and research. European Educational Research Journal, 9.1, 13-28.

Herchrich, S. \& Münte, T. F. \& Altenmüller, E. O. (2008). Unforgettable film music: the role of emotion in episodic long-term memory for music. BMC neuroscience, 9.1, 48.

LeDoux, J. (2003). Il cervello emotivo. Alle origini delle emozioni. Milano: Baldini \& Castoldi.

Lombardo, P. (2014). Memory and Imagination in Film: Scorsese, Lynch, Jarmusch, Van Sant. Berlin: Springer.

Malavasi, P.; Polenghi, S.; Rivoltella, P. C. (Ed.) (2005). Cinema, pratiche formative, educazione. Milano: Vita e Pensiero.

Meredith M.A. (2002) On the neural basis for multisensory convergence: a brief overview. Cognitive Brain Research. $14,31-40$.

Metz, C. (1964). Cinéma: langue o language? Comunicazioni, 4 (1), 52-90.

Moon, J. (2012) Esperienza, riflessione, apprendimento. Roma: Carocci.

Morin, E. (2001). I sette saperi necessari all'educazione del futuro. Milano: Cortina.

Plutchik R. (1980), Emotion: A Psychoevolutionary Synthesis. New York: Harper \& Row.

Read, H. E. (1958). Education through art. Oxford, (UK): Pantheon.

Rogoff, B. \& Lave, J. (Ed.) (1984) Everyday cognition: Its development in social context. Harvard: Harvard University Press.

Simpson, J. W., Delaney, J. M., Carroll, K. L., Hamilton, C. M., Kay, S. I., Kerlavage, M. S., \& Olson, J. L. (1998). Creating Meaning through Art. Teacher as Choice Maker. Prentice-Hall, Inc., Upper Saddle River, NJ: Simon \& Schuster/A Viacom Company, 07485.

Sroufe, L. A. (2000). Early relationships and the development of children. Infant Mental Health Journal, 21.1-2, 67-74.

Striano, M. (2000) I tempi e i luoghi dell'apprendere. Processi di apprendimento e contesti di formazione. Napoli: Liguori. 
Diacrises and mixed emotions in the relationship between music and art cinema: teacher learning and training through multimodal experiences

Nuti

Varani, A. (2000). Emozioni, apprendimento e ipermedialità. Psicologia e scuola, 98, 2.

Wertsch, J. (1985) Culture, communication and cognition. Cambridge (UK): Cambridge.

Zambaldi, N. (2016). Embodied Education al centro di un nuovo paradigma: un contributo da arte e teatro per un'interfaccia multimodale. Formazione \& Iinsegnamento. Rivista internazionale di Scienze dell'educazione e della formazione, 14.2, 333-340. 